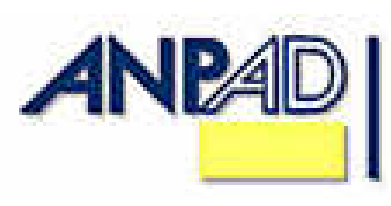

Available online at

http://www.anpad.org.br/bar

\title{
Willingness to Try Innovative Food Products: a Comparison between British and Brazilian Consumers
}

\author{
Marcia Dutra de Barcellos * \\ E-mail address: Marcia.Barcellos@pucrs.br \\ Pontifícia Universidade Católica do Rio Grande do Sul - PUCRS \\ Porto Alegre, RS, Brazil.
}

\section{Luís Kluwe Aguiar}

E-mail address: luis.aguiar@ rac.ac.uk

Royal Agricultural College - School of Business

Cirencester, Glo, United Kingdom.

\section{Gabriela Cardozo Ferreira}

E-mail address: gcferreira@pucrs.br

Pontifícia Universidade Católica do Rio Grande do Sul - PUCRS

Porto Alegre, RS, Brazil.

\section{Luciana Marques Vieira}

E-mail address: lmvieira@unisinos.br

Universidade do Vale do Rio dos Sinos

São Leopoldo, RS, Brazil.

\begin{abstract}
In this study we investigate the consumer's willingness to try innovative food products in the context of the metropolitan area of Porto Alegre in Brazil and Cirencester in England, UK. Innovation in the food industry is an important source of differentiation and a value-adding opportunity for managers to develop new products. Therefore, the adoption or rejection of innovative food products becomes strategic from a market point-of-view. Using the Domain Specific Innovativeness [DSI] scale and the Food Neophobia Scale [FNS], two surveys were carried out in Brazilian and British universities with 279 and 101 respondents, respectively. Consumers were not the most inclined to adopt innovations, but they were not afraid of new foods either, especially in the UK. Managers in the food industry could be missing out on opportunities to innovate more. The results provide strategic and unique information about consumers for the food industry, aiming at supporting the development of innovative food products.
\end{abstract}

Key words: consumer innovativeness; food products; food neophobia; Brazil; UK.

Received 29 August 2007; received in revised form 13 October 2008.

Copyright (C 2009 Brazilian Administration Review. All rights reserved, including rights for translation. Parts of this work may be quoted without prior knowledge on the condition that the source is identified.

* Corresponding author: Marcia Dutra de Barcellos

Pontifícia Universidade Católica do RS, Av. Ipiranga 6681, Prédio 50, $11^{\circ}$ andar, sala 1101, Porto Alegre, RS, 90619-900, Brazil. 


\section{INTRODUCTION}

It is well-known that consumers in general present some level of resistance in adopting innovation, especially in items of high technology. Rogers (1962), in his seminal work with the Innovation Adoption Curve model, segmented the adoption behaviour amongst five categories of individuals, based on their willingness to be more or less open to innovation. From innovators to laggards, individuals range on a continuum. The model, also known as Multi-Step Flow Theory or Diffusion of Innovation Theory, proposes that some consumers are more averse to the adoption of innovation than others, but it does not indicate clear boundaries of consumption behaviour to delineate the differences between the segments. Moreover, Rogers' model is based on the adoption of technological innovation and it is known that technology per se presents, to some consumers, barriers regarding how to use or operate a machine, a bank terminal or a gadget.

Nevertheless, consumers also show resistance to the adoption of new food products that are introduced into the market. This could be related to cultural habits, to socio-demographic behaviour, lifestyle or the period of life one is living. It is also known that some consumers are more traditional than others and these could be the 'gatekeepers' of innovation adoption in some societies.

The rejection of some food products may also be related to food neophobia, which could be defined as "a strong avoidance to try novel, unfamiliar foods", such as ethnic food, for example (Pliner \& Hobden, 1992, p. 105). For food-neophobic consumers, familiarity of food may be a central determinant of food acceptance, and constitute a barrier to the successful introduction of new food products in the market.

Eating habits of the Brazilian population, for instance, can vary considerably around the country. Not to mention Portuguese and Spanish, the southern region is also strongly influenced by Italian and German cuisine that came with the immigrants who colonized the region in the 1800s. In the northeast, the geographical proximity with the sea and the mix of Portuguese, African and Indigenous culinary habits since the XVI century has led to singular gastronomic characteristics (Souza \& Hardt, 2002). Such variety might have a positive impact on the adoption of new foods, although more traditional eating behaviour could also be expected due to the strong regional and cultural roots of conservative consumers.

In the United Kingdom [UK], according to data from Euromonitor (Global Market Information Database [GMID], 2006), traditional food habits are changing. Consumer interest in ethnic food is growing and stems from the presence of large and relatively recent immigrant communities that have brought South and East Asian, Latin American and Mediterranean cuisine to the food service industry. British people are also travelling more than they ever have, and are encountering new flavours and ingredients, which they want to replicate at home.

In addition, Euromonitor (GMID, 2006) data indicates that consumers from the UK are leading the way in ready meals, spending an average of US\$161 per person per annum on them. They also spend more than anyone else on prepared salads. UK ready meals tend to be a curious mixture of global recipes from around the world and old-fashioned home comfort food (often involving mashed potato) which few can find the time to cook from scratch. The British are also the largest buyers of chilled ready meals, with supermarket brands being the most popular. In this regard, British consumers might be less resistant to the adoption of new foods.

Furthermore, innovation constitutes an important competitive advantage for food companies. Innovative consumers constitute a key market segment to investigate, since they can propel novelties by being the first adopters of a food consumption pattern.

In the case of Brazil and in the UK, the analysis of the introduction of new food products to the market has never been addressed, and it is unclear how consumers, on average, would relate to the 
adoption of such foods. Therefore, investigating willingness to adopt or reject innovative food products becomes strategic to the food industry in both cases.

\section{THEORETICAL BACKGROUND}

Innovation in the food industry is an important source of differentiation and a value-adding opportunity for managers to develop new products. Hence, innovation constitutes a competitive advantage in the globalised agri-food scenario.

According to Michaut (2004), new products are vital for sustainability in today's markets. Innovation specifically provides corporate vitality, enhanced performance-price index for consumers and a much needed opportunity to differentiate from competitors (Fusco, 1994 as cited in Michaut, 2004). Moreover, inputs for innovation were found to have a positive impact on profitability (Capon, Farley, \& Hoenig, 1990 as cited in Michaut, 2004).

Costa and Jongen (2006) state that product innovation may to help to maintain a firm's growth (thereby protecting the interests of investors, employees and food chain actors), reduce the market risk, enhance the company's stock market value and increase competitiveness. Conversely, the authors state that the European food and beverage industry is quite conservative in the type of innovations it introduces to the market, with much lower Research and Development $[R \& D]$ investments than industries in other sectors.

One possible explanation, according to studies by Cooper (1994) and Costa and Jongen (2006), is that many food product introductions fail. Around $40 \%$ to $50 \%$ of new product introductions are off of retailers' shelves within a year, according to Ernst \& Young Global Client Consulting (1999). As a consequence of such negative product introduction results, the food sector strategy is characterized by a parsimonious development of innovations. Much of the innovation is based on brand extensions of the same product line, which is a less risky strategy (Grime, Diamantopoulus, \& Smith, 2002). Consumers also present a slow rate of change in eating preferences and habits. Furthermore, they tend to reject too much novelty in food, thereby constituting strong barriers to genuine innovation (Costa \& Jongen, 2006).

Nonetheless, innovative consumers represent a key market segment. They play an essential role in the success of a new product by legitimizing the novel product to other consumers (Huotilainen, Pirttilä-Bäckman, \& Tuorila, 2006).

There is considerable evidence that personality traits affect willingness to consume certain new or novel foods. According to Tuorila, Läahtenmaki, Pohjalainen and Lotti (2001), food neophobia is individual, although cultural and socio-economic influences have been reported in the literature. Flight, Leppard and Cox (2003), for example, hypothesised that urban subjects in comparison to rural subjects would have lower food neophobia. In a similar fashion, Socio-Economic Status [SES] would have a negative influence towards food neophobia, since greater disposable income to eat outside the home and greater educational status would provide greater knowledge of cultural cuisines and, therefore, less aversion to unfamiliar food, characterizing consumer innovativeness.

Generally, consumer innovativeness is considered difficult to measure. However, there is a consensus that there are different kinds of innovativeness and these could be innate or not. Innovativeness is conceptualized as "...a generalized consumer trait that exerts a positive effect on the trial probability of new offering across the broad spectrum of goods and services" (Steenkamp \& Giles, 2003, p. 369). Steenkamp, Hofstede and Wedel (1999, p. 57) define consumer innovativeness as "...the predisposition to buy new and different products and brands across a variety of goods and services". 
Nevertheless, Goldsmith and Hofacker (1991) distinguish between innate and Domain Specific Innovativeness. They developed the Domain Specific Innovativeness Scale [DSI] in order to measure consumer innovativeness for a specific product category, thus reflecting the consumer's tendency to adopt innovations within a specific domain of interest. In the food sector, according to Huotilainen et al. (2006), the DSI has been employed to measure innovation in delicatessen-type ham (McCarthy, O'Sullivan, \& O'Reilly, 1999), and wine (Goldsmith, d'Hauteville, \& Flynn, 1998). The scale comprises six items and, according to Roehrich (2004), it has proved to be unidimentional, highly reliable and presented with a high predictive validity. These are the reasons why this scale was selected to be tested in this study.

Pliner and Hobden (1992) developed and validated a 10-item verbal instrument Food Neophobia Scale [FNS] to quantify this individual trait. The scale has been used in many studies in the food consumption field (Bäckström, Pirttilä-Backman, \& Tuorila, 2004; Ritchey, Frank, Hursti, \& Tuorila, 2003; Tuorila et al., 2001), appearing to be a valid instrument for the characterization of consumer responses to unfamiliar foods.

\section{OBJECTIVES}

The aim of this study was twofold: firstly, to measure the extent consumers in the metropolitan area of Porto Alegre, capital of the southern state of Rio Grande do Sul in Brazil, and in Cirencester, in the UK were willing to try and use innovative food products. For this purpose, the scales of Domain Specific Innovativeness [DSI] proposed by Goldsmith and Hofacker (1991) and the Food Neophobia Scale [FNS] proposed by Pliner and Hobden (1992) were used.

When we consider the resistance to the adoption of innovation or even the rejection of some food products, it is necessary to consider the attributes that may influence purchase and consumption decision behaviour. In this sense the cultural trait seems to be one of the most important attributes in this regard and the reason for studying the behaviour of such a group of consumers. Lifestyle and the economic environment can also play an important role. The researchers were therefore motivated to investigate food consumption behaviour in two different cultural scenarios, such as the ones found in the metropolitan area of Porto Alegre, Brazil and in Cirencester, UK. We also aimed to measure the consumers' willingness to try new food products with a view to evaluating their adoption or rejection based on market results.

In addition, the research carried out also attempted to calibrate the food innovation adoption model considering an international context. For the first time, the proposed scales were validated in one region in Brazil and in the UK. This is highly desirable in the social and behavioural sciences, and also required for the development of general theories that are largely independent of cultural and historical context. It is crucial for consumer behaviour as an academic discipline that models developed in one country can be extended to others (Steenkamp \& Baumgartner, 1998). In this perspective, this research particularly addresses to the equivalence of constructs, samples and measurement.

\section{RESEARCH METHOD}

To comply with the proposed objectives, a survey was carried out in Porto Alegre's metropolitan area in Brazil with undergraduate students at two universities. At the same time, the survey was also conducted in Cirencester with undergraduate and postgraduate students from one university in the UK.

The survey comprised 28 questions divided in three sections. The first section was about the respondent's attitudes towards the purchase of new, different and innovative foods throughout the 
application of the 6-item Domain Specific Innovativeness Scale [DSI] developed by Goldsmith and Hofacker (1991). The five-point Likert scale items were anchored with (1) 'strongly disagree' and (5) 'strongly agree', with (3) corresponding to the neutral position 'neither agree nor disagree'. In addition, participants could choose option (9) 'I don't know' if they were unsure about the meaning of the question or if their influence in the shopping behaviour of food innovations was null. In this case, answers would be treated as missing values. The questions were coded so that a high score reflected higher levels of innovativeness. The theoretical range of scores for each of the measures was from 6 to 30 , i.e., the sum response to these six items provides a domain-specific innovativeness score that ranges from minimum 6 to maximum 30. Finally, following studies from Goldsmith and Hofacker (1991), Goldsmith, Freiden and Eastman (1995) and others (Hynes \& Lo, 2006; Phau \& Lo, 2004) subgroups of innovators and adopters (non-innovators) were identified within each sample.

The second section attempted to measure food neophobia with Pliner and Hobden's (1992) Food Neophobia Scale [FNS]. The 5-point Likert scale items were also anchored with (1) 'totally disagree' and (5) 'totally agree', with (3) corresponding to the neutral position 'neither agree nor disagree'. Option (9) corresponded to 'I don't know' and answers within this category were treated as missing values. The individual scores for neophobia were obtained by summing the 10-item scores, as described by the authors. Respondents were then categorized into subgroups of neophobics and nonneophobics.

Finally, the third section comprised of some demographic profiling questions as well as questions measuring the level of exposure to new technology, gadgets and specific novel foods.

In Brazil, 279 valid questionnaires were obtained. Consumers were surveyed using face-to-face interviews through the self-administered survey technique. 101 valid questionnaires were obtained with the same technique from consumers surveyed in the UK. The data collected was subjected to statistic-testing such as T-test and Chi-square analysis to assess the significance between different groups of respondents. Internal consistency of DSI and the FNS components was measured by Cronbach's alpha.

\section{RESULTS}

The results are presented in 4 sections. The first section comprises the socio-demographics of the interviewees; section 2 presents the results of the willingness to adopt new food products; and section 3 presents the results of the food neophobia level of the respondents. Finally, section 4 focuses on innovative food products recently sampled/purchased by the interviewed consumers.

\section{Socio-demographics and Purchase Habits}

The sample studied in Brazil consisted mainly of males (53\%) and in the UK, females were the majority (56.4\%). The majority of those interviewed both in Brazil and the UK were made up of undergraduate students, within the 18 to 29 age bracket. A sample of students is considered a valid and practical way to obtain research data, being applied in numerous studies worldwide (e.g., Flight et al., 2003; Goldsmith \& Hofacker, 1991) Regarding household status, in Brazil, most lived at home with either both or at least one of their parents (64.9\%), while in the UK most live with their partner/spouse (46.5\%). 55.2\% of the Brazilian respondents were born in cities with more than 500,000 inhabitants and $99 \%$ of the respondents stated that they lived in an urban area. On the other hand, the majority (43.6\%) of the British students were born in small cities (towns with less than 100.000 inhabitants) and $60.4 \%$ of them have been living in a rural area for the last 5 years. It is worth noting that small rural areas in the UK such as Cirencester are located near to large urban towns and are supplied by large retail chains. Although some bias might exist due to differences found in the place of birth and household situation within the samples, it is important to state that the geographic structure in Brazil 
and in the UK is quite different. In Brazil, people tend to agglomerate around urban areas and rural space is well defined. On the other hand, in the UK, rural areas are merged and in close boundaries with urban centres. For instance, food (and non-food) products supplied in those areas are the same as the ones found in big cities such as London. In Brazil, the assortment may vary according to the size of the city and regional characteristics (authors' note).

\section{Willingness to Try New Food Products: Results from the Domain Specific Innovativeness Scale [DSI]}

Table 1 presents the results obtained with the application of the Domain Innovativeness Scale in Brazil and in the UK.

Table 1: Means, Standard Deviation, Score and Reliability of the Domain Specific Innovativeness Scale [DSI]

\begin{tabular}{|l|c|c|c|c|}
\hline & \multicolumn{2}{|c|}{ BRA } & \multicolumn{2}{c|}{ UK } \\
& Mean & S.D & Mean & S.D \\
\hline $\begin{array}{l}\text { 1. I buy new, different or innovative foods before } \\
\text { anyone else I know. }\end{array}$ & 3.27 & 1.15 & 2.97 & 1.08 \\
\hline $\begin{array}{l}\text { 2. Generally I am amongst the first of my circle of } \\
\text { friends to buy new, different or innovative foods. }\end{array}$ & 2.98 & 1.11 & 2.95 & 1.08 \\
\hline $\begin{array}{l}\text { 3. Compared to my friends, I purchase more new, } \\
\text { different or innovative foods. }\end{array}$ & 3.11 & 1.12 & 3.08 & 1.05 \\
\hline $\begin{array}{l}\text { 4. If new, different or innovative foods are available in } \\
\text { shops and supermarkets I always purchase them.* }\end{array}$ & 3.99 & 1.01 & 3.91 & 1.15 \\
\hline $\begin{array}{l}\text { 5. Generally I am the first amongst my friends to } \\
\text { remember a brand of new, different or innovative } \\
\text { foods.* }\end{array}$ & 3.65 & 1.12 & 3.48 & 1.18 \\
\hline $\begin{array}{l}\text { 6. I do purchase new, different or innovative foods } \\
\text { even if I have not tasted/experienced them } \\
\text { beforehand.* }\end{array}$ & 3.57 & 1.32 & 3.54 & 1.46 \\
\hline DSI SUM SCORES & & & & $\mathbf{1 9 . 9 3}$ \\
\hline Cronbach's Alpha & $\mathbf{2 0 . 5 7}$ & $\mathbf{4 , 8 1}$ & $\mathbf{4 . 8 9}$ \\
\hline
\end{tabular}

Source: research data.

Means based on a 5-Point Likert Scale, where 1 corresponds to 'totally disagree', 3 corresponds to 'neither agree nor disagree' and 5 corresponds to 'totally disagree'.

*Original scale reverse items were changed for better comprehension

Means difference at the $5 \%$ level was not significant.

The theoretical range of the DSI. sum score is between 6 and 30. The mean score obtained in Brazil was 20.57, and in the UK it was 19.93. These results are consistent with several other studies (Goldsmith \& Flynn, 1992; Goldsmith et al., 1995) and were considered moderate. In general terms, the results also indicate that students in Brazil and in the UK have similar levels of innovativeness in regard to food products. As can be seen in details from Table 1, the calculated means value from all the variables is around 3, but there are no values above 4. This indicates that the respondents (either in Brazil or in the UK) are slightly inclined to adopt innovations related to the food sector. Students from both countries are "not amongst the first of their circle of friends to buy new, different or innovative foods", although they stated that they "always purchase different or innovative foods when they are available in shops and supermarkets". In that sense, the respondents are open to innovations in the food sector, even though they might be considered 'moderate' when it comes to adopting food innovations.

Nevertheless, to explore the sample characteristics in more detail, a DSI cut-off point was established by subtracting the lowest scores from the highest scores obtained in this study. Therefore, 
the cut-off-point was 23 (30-7) for the Brazilian and 20 (29-9) for the British sample. Those with DSI scores of 23 (Brazil) or 20 (UK) and over on the scale were identified as food innovators. Respondents with scores below that were identified as adopters (non-food innovators). Of the Brazilian sample, only $39.4 \%$ of the students were categorised as innovative. In the UK, innovative food consumers were the majority, 58.4\% of the studied sample. Not surprisingly, the results indicated that although presenting a similar general level, students in the UK were more innovative in regard to food products. Even considering the 'rural' environment where they live, the acceptance level of novel food products was higher. Perhaps in Brazil, more traditional eating habits of the students or their parents, or even the few marketing investments from the food sector, might help to explain these results.

Regarding scale reliability, using the SPSS package, the Cronbach's alpha test was carried out to measure the coefficient of reliability of the DSI scale. For the first section of the survey testing the respondent's willingness to the purchase of new, different and innovative foods, Cronbach's alpha coefficient was 0.798 in Brazil and 0.782 in the UK, which are high, thus showing a 'good correlation' amongst all the questions. Alpha coefficient ranges in value from 0 to 1 and may be used to describe the reliability of factors from a scale. The higher the score, the more reliable the generated scale is. Hair, Black, Babin, Anderson e Tatham (2006) has indicated 0.7 to be an acceptable reliability coefficient.

\section{Results from the Food Neophobia Scale}

Table 2 presents the results obtained from the Food Neophobia Scale in Brazil and in the UK.

Table 2: Means, Standard Deviation, Score and Reliability of the Food Neophobia Scale [FNS]

\begin{tabular}{|c|c|c|c|c|}
\hline & \multicolumn{2}{|c|}{$\begin{array}{c}\text { BRA } \\
n=279\end{array}$} & \multicolumn{2}{|c|}{$\begin{array}{c}\mathrm{UK} \\
\mathrm{N}=101\end{array}$} \\
\hline & Mean & S.D & Mean & S.D \\
\hline $\begin{array}{l}\text { 1. I am seldom tasting and experimenting new, } \\
\text { different or innovative foods.* }\end{array}$ & 2.67 & 1.16 & 2.88 & 1.19 \\
\hline 2. I do not trust new, different or innovative foods. & $2.00 * *$ & 0.96 & $2.11 * *$ & 1.12 \\
\hline $\begin{array}{l}\text { 3. I would not taste any food provided I know how it is } \\
\text { made. }\end{array}$ & 2.95 & 1.50 & 2.89 & 1.53 \\
\hline 4. I do not like foods from different cultures. ${ }^{*}$ & 2.14 & 1.28 & 1.89 & 1.26 \\
\hline $\begin{array}{l}\text { 5. Foods from different cultures from my own seem } \\
\text { strange to eat. }\end{array}$ & 2.60 & 1.23 & 2.01 & 1.22 \\
\hline $\begin{array}{l}\text { 6. In social events I would not taste new, different or } \\
\text { innovative foods.* }\end{array}$ & 2.03 & 1.10 & 1.95 & 1.26 \\
\hline $\begin{array}{l}\text { 7. I am afraid of eating things that I have not } \\
\text { tasted/experienced before. }\end{array}$ & 2.51 & 1.32 & 2.25 & 1.36 \\
\hline 8. I am very selective regarding the food I eat. & 3.27 & 1.35 & 3.07 & 1.35 \\
\hline 9. I do not eat everything.* & 2.83 & 1.49 & 2.54 & 1.50 \\
\hline $\begin{array}{l}\text { 10. I do not like going to places where foods from } \\
\text { different cultures from mine are served.* }\end{array}$ & 2.35 & 1.25 & 1.95 & 1.19 \\
\hline FNS SUM SCORES & 25.35 & 7.35 & 23.54 & 7.87 \\
\hline Cronbach's Alpha & \multicolumn{2}{|c|}{0.770} & \multicolumn{2}{|c|}{0.804} \\
\hline
\end{tabular}

Source: research data.

Means based on a 5-Point Likert Scale where 1 corresponds to 'totally disagree', 3 corresponds to 'neither agree nor disagree' and 5 corresponds to 'totally disagree'.

* Original scale reverse items were changed for better comprehension.

** indicate $0.01<\mathrm{p} 0.05$ (statically significant means difference).

Table 2 showed the items from the Food Neophobia Scale and in general they presented relatively low mean values (less than 3 for all the variables, except for item 8 "I' $m$ very selective regarding the 
food I eat", in both cases). This, therefore, indicates that the respondents are not afraid of new foods as they disagree with the majority of the assumptions presented in the survey. The only observed statically different mean was related to the statement "I do not trust new, different or innovative foods", with respondents from Brazil showing more disagreement (less food neophobia in this item).

The sum scores for neophobia were obtained by adding up the 10-item scores, as described by Pliner and Hobden (1992). The scores ranged from 10 to 45 (Brazil) and from 11 to 48 (UK), the theoretical range being from 10-50. Brazilian students obtained a DSI sum score of 25.35 and students in the UK presented a slightly lower score (23.54), which could be interpreted as being less scared of food innovations.

To investigate these findings more deeply, participants were divided into two groups by subtracting the lowest from the highest value obtained. Participants who scored from 10-34 (Brazil) or 10-36 (UK) were classified as 'non-neophobics' and those who scored from 35-45 (Brazil) or 37-48 (UK) were classified as 'neophobics'. In Brazil, 11.5\% of the respondents presented food neophobia, whilst in the UK only $5 \%$ were averse to food novelties.

In general, consumers are open to innovation, since they are not averse to innovative food products, especially in the UK. On the other hand, the results bring implications for the food industry in Brazil, which could attempt to be more innovative as it is felt that the innovations in food are rather restricted. In the UK, the means obtained with the FNS were in general lower, indicating even more favourable willingness to try and consume new foods. The already mentioned influence of ready meals and international cuisine in British food seems to have a positive relation in this regard, and future studies could address this issue.

The measure of the FNS scale reliability also generated a high Cronbach's alpha value at 0.770 in Brazil and 0.804 in the UK, confirming that the variables within the scale are correlated and valid. This also confirms the findings of Roehrich (2004) as a uni-dimensional set of data generates a high Cronbach's alpha value.

\section{Innovative Food Products Recently Experimented/Purchased}

Consumers were asked about their recent purchase/consumption of some innovative products launched by food industries in Brazil and in the UK, selected according to the criteria of the researchers.

In Brazil, the products were Light Pork Leg Sausage, Soy Milk, ready meals with beef (Beef Stroganoff, Bolognese Minced Beef or Beef with vegetables), Special Sausages (cheese, barbecue and Mexican flavoured), Rump Steak Flavoured Hamburgers and Hot Pockets (a microwavable snack). The results indicate that most consumers (from $67 \%$ to $82 \%$ ) have never tried the above mentioned products, with the exception of Rump Steak Flavoured Hamburger, experimented/purchased by $44.4 \%$ of the respondents. As stated before, possible explanations for this include the assumption that either the students or their parents might present a moderate or conservative shopping behaviour towards food innovations. DSI score was also found moderate and the majority of the students in Brazil were not the most prone to adopt food innovations. Personal preferences for innovative food products could also be considered, meaning that the selected innovative food products might not be amongst the most preferred. Nevertheless, students mentioned some other innovative products, most from the drinks and beverage sector: Ice Nescafé, Zero Coke, Coffe Mate Nestlé, Cereal bars, H2OH, Skol Lemon (beer) and Nissin Miojo Hot (pasta). Strong marketing campaigns from the drinks and beverage sector, as opposed to few investments in the food (meat and ready-to-eat) sector may also help to account for the results obtained in Brazil. In the UK, the selected innovative products were Quorn (meat substitute with soya), Soya Milk, Mongolian food, Venison, Horse meat and Organic maize biscuits. $71.3 \%$ to $94.1 \%$ of the respondents had never experimented or purchased the proposed innovative products with the exception of $43.6 \%$ of the respondents that have tried Venison meat, a traditional game meat in the UK. Place of purchase and inappropriate selection of the pooled innovative products may explain this, 
since products might not have been found where the surveyed students actually shop for food. Notwithstanding, students quoted some interesting innovative products they have tried, over 40 different and innovative food products were quoted, such as fruit smoothies, deep fried insects, quinoa (grain originally from Bolivia), pigeon, yellow tomatoes, bio-live yoghurt, chilli flavoured cereal bars, Korean National food (barbecue, marinated radish, etc), various types of food from the West Indies, and others.

Therefore, based on the results, UK respondents seem much more open to perceive innovative products, even though most of them did not try the proposed innovative products. Nevertheless, they provided a good source of information regarding innovative products, and one realizes the strong appeal of organic products and ethnic cuisine for them. In Brazil, students are more conservative in this regard.

\section{DISCUSSION AND CONCLUSIONS}

This study addresses consumers' behaviour regarding their willingness to try innovative food products. Since the study of consumer behaviour and the validation of scales in an international context are highly desirable in the social and behavioural sciences, this study succeeded in demonstrating that the use of the Domain Specific Innovativeness [DSI] and the Food Neophobia Scale [FNS] are valid for the cases of Porto Alegre's metropolitan area, Brazil and Cirencester, UK. Hence, the importance of the validation of the scales would support the development of general theories that are largely independent of cultural and historical context.

In Brazil, the fact that the respondents are more prone to innovation in technology and less open to trying new foods could be attributed to different reasons. On the one hand, being less phobic towards technology could be attributed to 'following the trend' or 'keeping abreast of their peers'. The fact that nearly $65 \%$ of the respondents live with their parents may also indicate that their role in food purchasing and preparation is secondary. Usually an older member of the family would act as initiator or decider, thus restricting the role of young adults living at home to being one of influencer only. Seldom would young adults be responsible for the weekly shopping of the family.

Furthermore, in Brazil, another factor that impacts on people's willingness to try new food products is the low cost of unskilled labour. This means that professionals such as maids are quite commonplace in households, and cooking is one of their most appreciated duties. In that sense, many people have lunch or dinner at home, with the food prepared especially for them. Normally, the food that is prepared would be traditional dishes from Brazilian cuisine, not innovative in general. In addition, in Brazil one can find a special category of restaurants called buffet por quilo, where you have a vast array of food (different types of salads, pasta, meat, rice, beans, fruit and desserts), and you pay according to how much food you put on your plate, normally at a fair cheap price. Such variety at a competitive price may help account for why pre-ready foods are not so popular.

However, the results do confirm that students themselves shop for food, as can be observed from the self-reported innovative food products quoted in the survey. In that sense, food industries could benefit by supplying innovative snacks and ready-to-eat products to young consumers. In addition, the influence of young consumers in the familiar food shopping behaviour cannot be ignored. Even indirect effects can exert significant changes in the shopping basket (Nørgaard, Brunsø, Christensen, \& Mikkelsen, 2007).

In the UK, according to data from Euromonitor (GMID, 2006), traditional British dishes normally centre on meat or fish, with potatoes and other vegetables, such as carrots, peas, sprouts and cabbage. Traditional desserts include pastry dishes such as apple pie, cakes and sponge puddings. Such traditional meals are consumed less and less in the UK, however, due to the influence of a number of international cuisines and ready meals on the British diet. Families often cook with rice or pasta 
instead of potatoes; buy ready meals in varieties such as Chinese, Indian or Thai; or consume readymade pizzas. The results from this study confirm this trend, and students from Cirencester are moderately willing to try new food products, especially those related to organic or ethnic cuisine.

Moreover, as the data analyzed shows that food neophobia is relatively low in both cases, it is felt that the food industry could be missing an opportunity by not being innovative enough, especially in Brazil. The innovative products launched by the drinks and beverage sector seem to be leading consumers' experiences, thereby showing the food industry that more can be developed. In Europe, the food and beverage industry, despite being considered conservative in the type of innovations it introduces (Costa \& Jongen, 2006), is showing higher product development than food industries in Brazil, especially considering organic, cultural and ethnic food innovations.

It is known that familiarity with foods can decrease neophobia (Pliner \& Hobden, 1992). Consequently, the British cultural mix may be responsible for the low rates of food neophobia presented in this study due to a greater general exposure to so-called 'ethnic' foods or to the great extent ready meals represent on British food expenditure.

Moreover, considering the highly competitive business environment in many markets in the world, the food industry in Brazil could be operating in a less competitive environment. In Brazil, with the exception of some food multinationals, food manufacturers supply mostly according to a regional demand. In time, Brazilian consumers could manifest all their potential to adopt new food products, since there is also a great cultural mix within the population. This could especially be true in the case of younger consumers due to globalisation issues.

In that sense, although the studied samples presented slightly different socio-economic profiles (the British respondents were older, more independent and living in a rural area, while Brazilian respondents were younger, dependent on their parents and mainly urban), there appears to be a confluence towards a standardized global consumption pattern. The moderate willingness to try innovative food products and the low rate of food neophobia was found to be statistically similar in both cases even though some differences were expected.

Finally, the results of the survey provide strategic and unique information about consumers to the food industry. For managers in the food industry this could support the development of food products based on consumer perception towards innovation. Further probabilistic studies using the Food Neophobia Scale [FNS] and the Domain Specific Innovativeness [DSI] scales could provide further insights into the consumer's willingness to try novel foods in Brazil and in the UK. This would also enhance the calibration of the scales for the international context.

\section{Research Limitations and Future Avenues}

It is important to state that this study focused on the willingness to try innovative food products, with analyses based on a non-probability sample of students in Brazil and in the UK. Therefore, our findings apply specifically within the demographic characteristics of the samples, and descriptive generalizations in terms of the public at large must be treated with caution. Future research will benefit from including other potential determinants of willingness to adopt new food, like economic and cultural factors, and from drawing on larger probability samples using, for instance, random sample selection techniques. However due to time and resource constraints it was not possible to accomplish this in this study. Although this is a relatively small-scale study, the results presented have been of value to inform the development of consumer orientated food innovation strategies.

Apparently, consumers identified cultural and ethnic foods as innovations despite the fact that these are actually food categories rather than innovative food products. Nonetheless, a product is considered to be an innovation if it is perceived as new by an individual or other unit of adoption (Rogers, 1962). According to Michaut (2004), there are different degrees and types of innovations, all consisting of a change compared to existing products, but offering considerable variation in the level of change. Innovations can follow a company's perspective (newness to the company, technological 
newness) or a consumer's perspective (market newness, consumer's benefit newness). From the company perspective, technological newness is challenging and critical, but risky; yet product market success is more likely to be affected by consumers' assessment of the product since they constitute the ultimate target of the product (Michaut, 2004). In that sense, what consumers consider innovative food products might be the true treasure arch to food companies willing to succeed in such a dynamic market, i.e., the technology push of the food sector can not forget to be market oriented. The authors plan to keep on with future research to further investigate these open avenues. Additional research could also explore differences within 'rural' and 'urban' consumers in regard to innovativeness, as well as other sociodemographics of interest. These sociodemographic differences may also be considered in public policies regarding food consumption.

In addition, further research could investigate young consumers' buying and eating behaviour of snacks, drinks and ready-to-eat dishes, as it is expected that for this category they might act as the main decider. Finally, considering that half of the DSI items compare participants' behaviours to their friends it would be advisable to check the extent to which participants have such close relationships. This information could reinforce the obtained results, although its reliability and validity are well documented in the literature (Goldsmith \& Flynn, 1992; Goldsmith \& Hofacker, 1991; Goldsmith et al., 1995; Hynes \& Lo, 2006; Phau \& Lo, 2004).

\section{REFERENCES}

Bäckström, A., Pirttilä-Backman, A. M., \& Tuorila, H. (2004). Willingness to try new foods as predicted by social representations and attitude and trait scales. Appetite, 43(1), 75-83.

Cooper, R. G. (1994). New products: factors that drive success. International Marketing Review, $11(1), 60-76$.

Costa, A. I. A., \& Jongen, W. M. F. (2006). New insights into consumer-led food product development. Trends in Food Science \& Technology, 17(8), 457-465.

Ernst \& Young Global Client Consulting. (1999). Efficient product introductions: the development of value-creating relationships (Report n. 0264H / 1999), Brussels, Belgium, Author.

Flight, I., Leppard, P., \& Cox, D. N. (2003). Food neophobia and associations with cultural diversity and socio-economic status amongst rural and urban Australian adolescents. Appetite, 41(1), 5159 .

Global Market Information Database. (2006, May 26). Consumer lifestyles - UK. Retrieved 7 July, 2007, from http://www.euromonitor.com/gmid

Goldsmith R. E., \& Hofacker, C. F. (1991). Measuring consumer innovativeness. Journal of Academy Marketing Science, 19(3), 209-222.

Goldsmith, R. E., \& Flynn, L. R (1992). The domain specific innovativeness scale: theoretical and pratical dimensions. European Journal of Marketing, 26(12), 42-55.

Goldsmith, R. E., Freiden, J. B., \& Eastman, J. K (1995). The generality/specificity issue in consumer innovativeness research, Technovation, 15(10), 601-612.

Goldsmith, R., d'Hauteville, F., \& Flynn, L. (1998). Theory and measurement of consumer innovativeness: a transnational evaluation. European Journal of Marketing, 32(3/4), 340-353.

Grime, I., Diamantopoulus, A., \& Smith, G. (2002) Consumer evaluation of extensions and their effect on core brand. European Journal of Marketing, 36(11/12), 1415-1438. 
Hair, J. F., Black, B., Babin, B., Anderson, R. E., \& Tatham, R. L. (2006). Multivariate data analysis (6th ed.). Upper Saddle River, New Jersey: Pearson/Prentice Hall.

Huotilainen, A., Pirttilä-Bäckman, A. M., \& Tuorila H. (2006). How innovativeness relates to social representation of new foods and to the willingness to try and use such foods. Food Quality and Preference, 17(5), 353-361.

Hynes, N., \& Lo, S. (2006). Innovativeness and consumer involvement in the Chinese market. Singapore Management Review, 28(2), 31-46.

McCarthy, M., O'Sullivan, C., \& O'Reilly, S. (1999). Pre-identification of first buyers of a new food product. British Food Journal, 101(11), 842-856.

Michaut, A. M. K. (2004). Consumer response to innovative products with application to foods. $\mathrm{PhD}$ Thesis, Wageningen University, Wageningen, The Netherlands.

Nørgaard, M. K., Brunsø, K., Christensen, P. H., \& Mikkelsen, M. R. (2007). Children's influence on and participation in the family decision process during food buying. Young Consumers: Insight and Ideas for Responsible Marketers, 8(3), 197-216.

Phau, I., \& Lo, C. C. (2004). Profiling fashion innovators: a study of self-concept, impulse buying and Internet purchase intent. Journal of Fashion Marketing and Management, 8(4), 399-411.

Pliner, P., \& Hobden, K. (1992). Development of a scale to measure the trait food neophobia. Appetite, $19(2), 105-120$.

Ritchey, P. N., Frank, R. A., Hursti, U. K., \& Tuorila, H. (2003). Validation and cross-national comparison of the food neophobia scale (FNS) using confirmatory factor analysis. Appetite, $40(2), 163-173$.

Roehrich, G. (2004). Consumer innovativeness: concepts and measurements. Journal of Business Research, 57(6), 671- 677.

Rogers, E. M. (1962). Diffusion of innovations. New York: Free Press.

Souza, M. D. C. A., \& Hardt, P. P. (2002, August). Evolução dos hábitos alimentares no Brasil. Revista Brasil Alimentos, 15, 32-39.

Steenkamp, J. B. E. M., \& Baumgartner, H. (1998). Assessing measurement invariance in crossnational consumer research. Journal of Consumer Research, 25(1), 78-90.

Steenkamp, J. B. E. M., \& Gielens, K. (2003). Consumer and market drivers of the trial probability of new consumer packaged goods. Journal of Consumer Research, 30(3), 368-384.

Steenkamp, J. B. E. M., Hofstede, F. ter, \& Wedel, M. (1999). A cross-national investigation into the individual and national cultural antecedents of consumer innovativeness. Journal of Marketing, 63(2), 55-69.

Tuorila, H., Läahtenmaki, L., Pohjalainen, L., \& Lotti L. (2001). Food neophobia among the Finns and related responses to familiar and unfamiliar foods. Food Quality and Preference, 12(1), 29-37. 